\title{
Investigation of the reactivity of propanil using cyclic voltammetric methods
}

\author{
Ayanthi Navaratne*, Namal Priyantha and Udaya Rodrigo \\ Department of Chemistry, Faculty of Science, University of Peradeniya, Peradeniya.
}

Revised: 05 December 2007 ; Accepted: 23 January 2008

\begin{abstract}
The stability and hence the reactivity of the herbicide, propanil [N-(3,4-dichlorophenyl) propionamide], strongly depends on $\mathrm{pH}$ of the medium and freshness of the solution. According to cyclic voltammetric investigation, propanil is fairly stable in mixed water/ethanol medium between $\mathrm{pH}=4$ and $\mathrm{pH}=7$ for a period of ten weeks. However, in strongly acidic medium $(\mathrm{pH}=1)$, its degradation which results in 3,4dichloroaniline (3,4-DCA) follows first order kinetics with an apparent rate constant of $5.33 \times 10^{-8} \mathrm{~s}^{-1}$, while in strongly basic medium ( $\mathrm{pH}=13)$, it undergoes faster degradation. 3,4-DCA is electroactive and its fresh solutions mimic the behaviour of propanil after degradation. Adsorption characteristics of propanil are also $\mathrm{pH}$ dependent, and its main degraded product, 3,4-DCA, is irreversibly adsorbed onto glassy carbon surfaces in an extremely basic medium.
\end{abstract}

Keywords: Degradation, electrochemical, pesticides, propanil, reactivity, 3,4-dichloroaniline

\section{INTRODUCTION}

Propanil [N-(3,4-dichlorophenyl)propionamide] commonly known as 3,4-DPA (Figure 1) is a herbicide used all over the world for over 40 years to control broad leaved and grassy weeds, especially in the rice fields ${ }^{1,2}$. Propanil is non-persistent and it is primarily degraded into 3,4dichloroaniline (3,4-DCA), and further into 3,3',4,4'tetrachloroazobenzene (TCAB), depending upon the conditions of exposure ${ }^{3}$. When applied as a weedicide

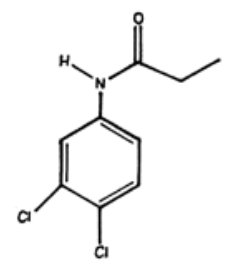

Figure 1: The structure of propanil propanil and its residues get into the environment, and possibly into food commodities ${ }^{4,5}$.

Many analytical methods have already been developed for the detection of propanil and its residues. Gas chromatography with nitrogen-phosphorus ${ }^{6}$, electron capture $^{7}$ and mass spectrometric detection ${ }^{8}$, liquid chromatography with diode array detection ${ }^{9}$, various immunoassay techniques ${ }^{10,11}$ and amperometry based on catalytic reduction in the presence of metalloporphyrins ${ }^{12}$ are a few modern methods that have been recently reported for the detection of propanil in different types of sample matrices. Solid-phase microextraction steps have also been coupled with either chromatographic detection ${ }^{13}$ or enzyme-linked immunoassay ${ }^{14}$ to improve sensitivity of the method ${ }^{12}$. Furthermore, electroanalytical methods have been developed to detect the primary residue of propanil, 3,4-DCA, using modified electrodes ${ }^{15}$.

Although detection methods for propanil and its residues have been significantly advanced in the recent past, not much attention has been focused on the investigation of kinetics of degradation and adsorption aspects. Such studies would be essential to understand the fate of propanil in the environment. Among reported studies, photodegradation of propanil in water and soil under normal environmental conditions, as well as in aqueous solutions under simulated solar irradiation with a photocatalyst ${ }^{16,17}$, adsorption-desorption characteristics in soil-fly ash mixtures through isotherm analysis ${ }^{18}$, and electrochemical oxidation of propanil and related $\mathrm{N}$-substituted amides through voltammetric methods ${ }^{19}$ have been attractive. Additionally, electro-catalytic action of organo halides on metallic surfaces and mechanistic investigation of the reductive cleavage of the carbonhalogen bond have been recently reported ${ }^{20,21}$. However, 
determination of the fate of propanil requires continuous monitoring of the levels of propanil in the environment to reach a firm conclusion.

The objective of this research was to employ cyclic voltammetric methods for the detection of propanil, in order to investigate the stability and reactivity of propanil together with its adsorption characteristics over a wide $\mathrm{pH}$ range of 1.0 to 13.0. The conclusions of such studies would be important, not only for the development of kinetics and adsorption models to be extended for the prediction of the fate of propanil in the environment, but also for updating the tolerance limits and risk assessment of this heavily used anilide pesticide.

\section{METHODS AND MATERIALS}

Materials: Analytical grade potassium chloride, sodium hydroxide, potassium hydrogen phthalate (KHP), potassium hydrogen orthophsphate and ethanol $(99.99 \%)$, used for the preparation of electrolyte solutions, and 3,4-DCA were purchased from Sigma-Aldrich (USA). High purity $\mathrm{N}$-(3,4-dichlorophenyl) propionamide (propanil) was a donation from the Department of Agriculture, Peradeniya, which was further recrystallized before use.

Sample preparation: All aqueous electrolyte solutions were prepared in $20 \%$ ethanol using freshly distilled water. All electrochemical experiments were carried out under $\mathrm{N}_{2}$ atmosphere. The $\mathrm{pH}$ was measured with an Orion Model 420A meter, equipped with an Orion $\mathrm{pH}$ electrode (Thermo Orion, USA).

Instrumentation: Cyclic voltammetry was performed with a CV-1B cyclic voltammograph and recorded on a Model 240 R X-Y recorder (both from Bioanalytical Systems, USA). All potentials were reported with respect to the saturated calomel reference electrode (SCE). Glassy carbon (GC) electrode and the platinum wire electrode served as the working and the counter electrodes, respectively.

\section{RESULTS AND DISCUSSION}

Cyclic voltammetry of $1.0 \times 10^{-3} \mathrm{~mol} \mathrm{dm}^{-3}$ propanil, freshly prepared in $\mathrm{pH}=7$ phosphate buffer $(0.1 \mathrm{~mol}$ $\mathrm{dm}^{-3}$ ) in ethanol/water (1:4) solvent system, indicates that propanil is electrochemically active, showing a strong oxidation peak centred at $+1.45 \mathrm{~V}$ (Figure 2a). Due to the low solubility of propanil in distilled water, a mixed solvent system (ethanol/water 1:4) was used in this study. It is also important to state that the medium is still $80 \%$ water, and hence $\mathrm{pH}$ corrections to account for solvent effects are not necessary. Careful voltammetric characterization experiments conducted at regular time intervals for a period of ten weeks showed that the major oxidation peak changed neither its position nor its magnitude significantly at $\mathrm{pH}=7$ (Figure 2b). Similar results were also observed in solutions of $\mathrm{pH}$ between 4 and 7 suggesting that propanil is fairly stable within these $\mathrm{pH}$ values, which is in agreement with our previous studies $^{15}$.

However, drastic changes in the voltammetric behavior were observed beyond this $\mathrm{pH}$ range. Fresh solutions of propanil at $1.0 \times 10^{-3} \mathrm{~mol} \mathrm{dm}^{-3}$ concentration level did not show any electrochemical activity within the working potential range at $\mathrm{pH}=1$ (Figure $3 \mathrm{a}$ ), indicating the electroinactivity of propanil at this $\mathrm{pH}$. This is probably due to the interference of the oxidation peak of propanil with the solvent breakdown process. However, one irreversible oxidation peak, and one oxidation/ reduction couple appeared after one week, indicating the change in reactivity of propanil with exposure to very low $\mathrm{pH}$. Monitoring the activity of propanil for longer periods at $\mathrm{pH}=1$ indicated that the intensity of the peaks, which appeared after one week, significantly increased with time (Figure 3b).

Further electrochemical investigation reveals that the intensities of these peaks were decreased during continuous scanning due to the decrease in the concentration gradient under unstirred condition, as expected (Figure 4). However, no chemisorption effects were encountered at this $\mathrm{pH}$ because thorough rinsing of the electrode with water and efficient stirring of the electrolyte solution were able to regenerate the electrochemical activity as observed in the first scan.

Interestingly, electrochemical behaviour of propanil after 10 weeks and that of a fresh solution of 3,4-DCA are equivalent at $\mathrm{pH}=1$ (Figures $3 \mathrm{~b}$ and 5 ). It is therefore suggested that propanil undergoes slow degradation yielding 3,4-DCA under extremely acidic conditions. Consequently electrochemical characteristics of propanil observed under such condition are attributed to the electroactivity of 3,4-DCA. Detailed investigation of cyclic voltammetric features in Figure $3 \mathrm{~b}$ indicated that peak 3 did not appear in the first scan which was started from the cathodic end although peak 1 appeared, followed by peak 2 . Thus the product of the oxidation reaction associated with peak 1 is the reactant for the process associated with peak 2 followed by subsequent oxidation giving rise to peak 3 . It is suggested that headto-tail oxidative coupling of 3,4-DCA, the degraded product of propanil as shown below, is responsible for 

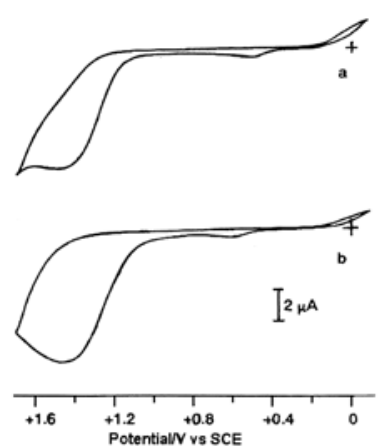

Figure 2: Cyclic voltammograms of $1.0 \times 10^{-3}$ mol $\mathrm{dm}^{-3}$ propanil in $\mathrm{pH}=7$ phosphate buffer $\left(0.1 \mathrm{~mol} \mathrm{dm}^{-3}\right)$ under $\mathrm{N}_{2}$ saturated at a scan rate of $50 \mathrm{mV} \mathrm{s}^{-1}$ (a) at the time of preparation (b) 10 weeks after preparation.

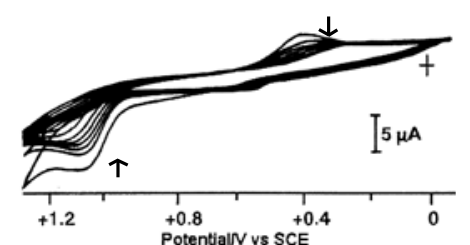

Figure 4: Continuous scanning responses of $1.0 \times 10^{-3}$ mol dm ${ }^{-3}$ propanil in $\mathrm{pH}=1 \mathrm{KCl} / \mathrm{HCl}(0.2$ mol $\mathrm{dm}^{-3}$ ) under $\mathrm{N}_{2}$ saturated at a scan rate of $50 \mathrm{mV} \mathrm{s}^{-1}$ recorded one week after solution preparation. Arrows indicate the direction of the shift during scanning.

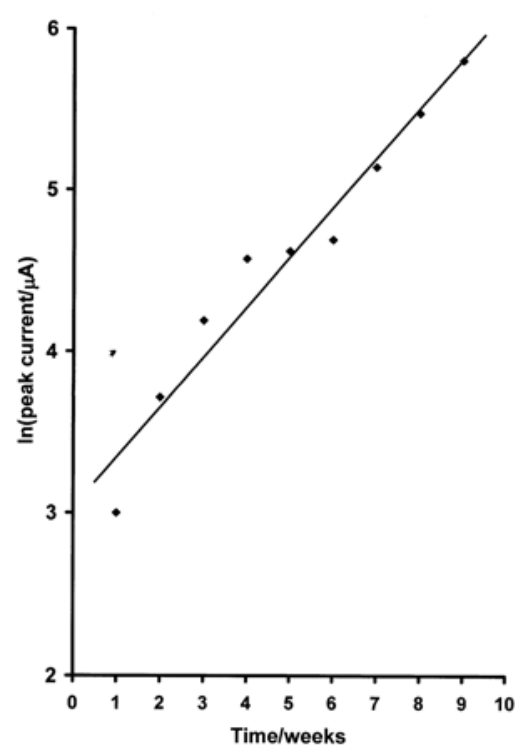

Figure 6: The variation of the logarithmic peak current for the oxidation of propanil at $\mathrm{pH}=1$ with time (The regression coefficient, $\mathrm{R}^{2}=0.95812$ ).

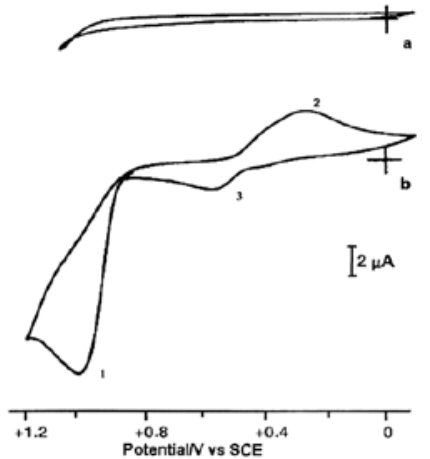

Figure 3: Cyclic voltammograms of $1.0 \times 10^{-3}$ mol dm ${ }^{-3}$ propanil in $\mathrm{pH}=1 \mathrm{KCl} / \mathrm{HCl}$ $\left(0.2 \mathrm{~mol} \mathrm{dm}^{-3}\right)$ under $\mathrm{N}_{2}$ saturated at a scan rate of $50 \mathrm{mV} \mathrm{s}^{-1}$ recorded (a) at the time of preparation (b) 10 weeks after solution preparation.

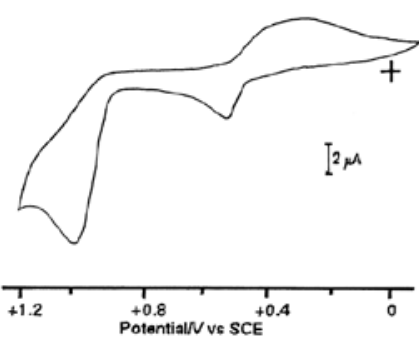

Figure 5: Cyclic voltammogram of $1.0 \times 10^{-3}$ mol dm ${ }^{-3}$ fresh solution of 3,4-DCA in $\mathrm{pH}=1 \mathrm{KCl} / \mathrm{HCl}\left(0.2 \mathrm{~mol} \mathrm{dm}^{-3}\right)$ under $\mathrm{N}_{2}$ saturated at a scan rate of $50 \mathrm{mV} \mathrm{s}^{-1}$.

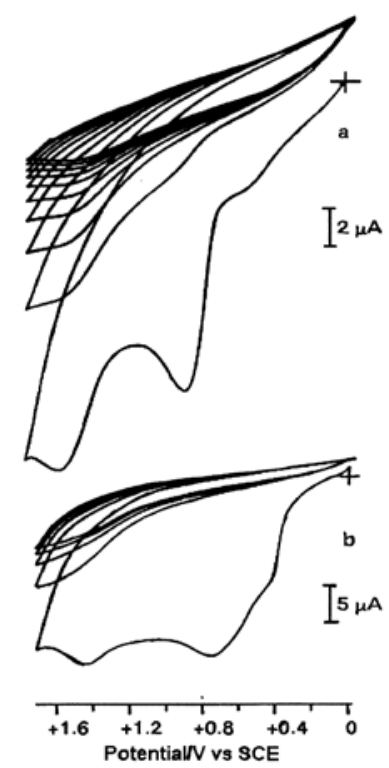

Figure 7: Cyclic voltammograms of a fresh solution of $1.0 \times 10^{-3} \mathrm{~mol} \mathrm{dm}^{-3}$ (a) propanil and (b) 3,4DCA in $\mathrm{pH}=13 \mathrm{KHP} / \mathrm{NaOH}\left(0.2 \mathrm{~mol} \mathrm{dm}^{-3}\right)$ under $\mathrm{N}_{2}$ saturated. Scan rate: $50 \mathrm{mV} \mathrm{s}^{-1}$. 
<smiles>CNc1ccc(Cl)c(Cl)c1</smiles>

the oxidation peak at $+1.0 \mathrm{~V}$ (peak 1). The product of the above oxidation reaction would undergo the following reversible process giving rise to peaks 2 and 3. A similar mechanism has already bean proposed for $\mathrm{p}$-chloroaniline at $\mathrm{pH}<4$ using an electrochemical method ${ }^{22}$.<smiles>[NH3+]c1ccc(Nc2ccc(OCCCCN=C3C=CC(=Nc4ccc(Cl)c(Cl)c4)C(Cl)=C3)c(Cl)c2)c(Cl)c1</smiles>

The kinetics of the degradation process of propanil at $\mathrm{pH}=1$ can be followed by monitoring the rate of increase in the current of the major oxidation peak at $+1.0 \mathrm{~V}$, which is due to the presence of 3,4-DCA. This reaction follows first order kinetics according to the linear plot between the logarithmic peak current and the time of measurement (Figure 6). The slope of the plot, the apparent rate constant associated with the degradation process, is determined to be $5.33 \times 10^{-8} \mathrm{~s}^{-1}$. This demonstrates that the reactivity of propanil can be indirectly monitored by observing the electrochemical activity of the degraded product, 3,4DCA.

The behaviour of propanil in basic medium is much different from that in acidic medium in many respects. Fresh solutions of propanil at $\mathrm{pH}=13$ result in three irrerversible oxidation peaks at $+0.47 \mathrm{~V},+0.80 \mathrm{~V}$ and $+1.50 \mathrm{~V}$ (Figure $7 \mathrm{a}$ ). However, unlike at $\mathrm{pH}=1$, electrochemical activity is not significantly altered with

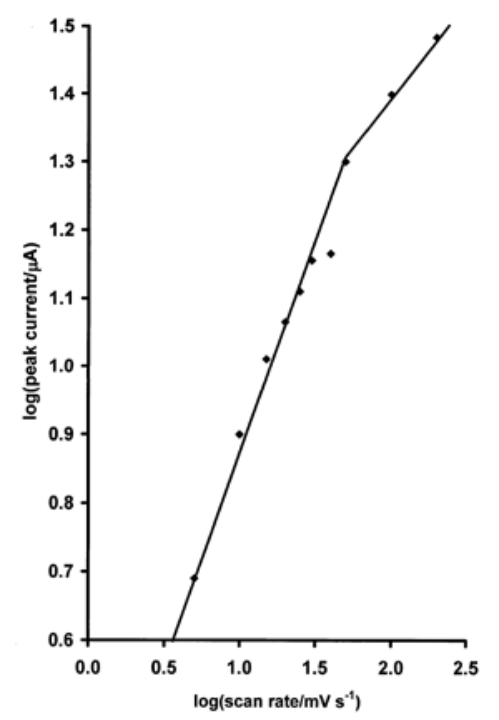

Figure 8: The plot of $\log \left(\mathrm{i}_{\mathrm{p}} / \mu \mathrm{A}\right)$ vs. $\left(\log \left(v / \mathrm{mV} \mathrm{s}^{-1}\right)\right.$, where $i_{p}$ is the peak current and $v$ is the potential scan rate, for the oxidation of propanil at $\mathrm{pH}=13$. time. Furthermore, the electrochemical behaviour of a fresh solution of 3,4-DCA at $\mathrm{pH}=13$ is very much similar to the electrochemistry of a fresh solution of propanil at the same $\mathrm{pH}$ (Figure 7b). Therefore, it is suggested that propanil undergo base hydrolysis due to the nucleophilic attack of $\mathrm{OH}^{-}$at the carbonyl position of propanil forming 3,4-DCA. According to electrochemical observations, base hydrolysis is faster, and the electroactivity of propanil observed for a fresh solution is due to the presence of 3,4-DCA. Further, the presence of different anionic constituents, namely $\mathrm{KCl} / \mathrm{NaOH}$ mixture (both at 0.1 $\mathrm{mol} \mathrm{dm}{ }^{-3}$ ), does not alter the electrochemistry of propanil solutions at $\mathrm{pH}=13$.

Continuous cyclic voltammetric scans recorded at $\mathrm{pH}=13$ indicate that the intensity of all the oxidation peaks is drastically decreased even at the second scan (Figure 7a). However, in contrast to the observations made at $\mathrm{pH}=1$, rinsing the electrode and stirring the solution did not reproduce the initial voltammetric behaviour, indicating that the electrochemically degraded product, 3,4-DCA, which is formed rapidly, would have strongly adsorbed on to the glassy carbon surface during the first few potential scans. An attempt to make electrochemical cleaning of the surface through application of the starting potential for a period of few minutes prior to the potential scan also failed to reproduce the voltammetric behaviour, confirming irrerversible adsorption of 3,4-DCA, or electrochemical degradation of 3,4-DCA forming electroinactive compounds. Such observations lead to the suggestion that irreversible adsorption of the degraded products of propanil take place at slower rates under real environmental conditions even at moderate $\mathrm{pH}$ values.

Adsorption characteristics of propanil were further investigated by analyzing the variation of peak current $\left(i_{p}\right)$ of the oxidation peak at $+1.50 \mathrm{~V}(\mathrm{pH}=13)$ with the potential scan rate $(v)$. The plot of $\log \left(\mathrm{i}_{\mathrm{p}}\right) \mathrm{vs} . \log (\mathrm{v})$ results in a slope of 0.7 at low scan rates and of 0.4 at high scan rates (Figure 8 ). This clearly suggests that the oxidation process at low scan rates is a combination of adsorption and diffusion. However, increase in the scan rate would change the rate-limiting step of the oxidation process as diffusion-controlled, although strong adsorption may appear as a follow-up step.

\section{CONCLUSION}

[N-(3,4-dichlorophenyl)propionamide], propanil, is fairly stable between $\mathrm{pH}=4$ and $\mathrm{pH}=7$, and its electroactivity within this $\mathrm{pH}$ range remains unchanged for a period of ten weeks. However, it undergoes degradation producing 3,4-dichloroaniline (3,4-DCA) in strongly acidic or basic media, and the rate of degradation strongly depends on the 
$\mathrm{pH}$ of the medium. It is slow at $\mathrm{pH}=1$ with an apparent rate constant of $5.33 \times 10^{-8} \mathrm{~s}^{-1}$, while the degradation is faster at $\mathrm{pH}=13$ due to the nucleophilic attack of $\mathrm{OH}^{-}$ at the carbonyl position. Electrochemical features of a fresh solution of 3,4-DCA and a solution of propanil ten weeks after preparation are equivalent at $\mathrm{pH}=1$. Nevertheless, electrochemical activity of fresh solutions of 3,4-DCA at $\mathrm{pH}=13$, which is markedly different from that at $\mathrm{pH}=1$, is similar to the activity of a fresh solution propanil at the same $\mathrm{pH}$. It is therefore concluded that the electroactivty of propanil at extreme $\mathrm{pH}$ values is due to the presence of 3,4-DCA, and not due to propanil. Similar studies would lead to the understanding of the fate of pesticides in the environment through design of models for kinetics, adsorption/desorption, and pesticide degradation pathways.

\section{Acknowledgement}

The authors wish to acknowledge the National Science Foundation of Sri Lanka for providing the research grant RG/99/C/06.

\section{References}

1. Hill J.E., Smith R.J. \& Bayer D.E. (1994). Rice weed control - current technology and emerging issues in temperate rice. Australian Journal of Experimental Agriculture 34: 1021-1029.

2. Perera A., Burleigh J.R. \& Davis C.B. (1999). Movement and retention of propanil in a paddy-riverine wetland system in Sri Lanka. Agriculture, Ecosystems and Environment 72(3): 255-263.

3. McMillan D.C., Leakey J.E.A., Arlotto M.P., McMillan J. \& Hinson J.A. (1990). Metabolism of the arylamide herbicide propanil, effects of propanil and its derivatives on hepatic-microsomal drug-metabolizingenzymes in the rat. Toxicology and Applied Pharmacology 103(1): 102-112.

4. Santos T.C.R., Rocha J.C., Alonso R.M., Martinez E., Ibanez C. \& Barcelo D. (1998). Rapid degradation of propanil in rice crop fields. Environmental Science and Technology 32(22): 3479-3484.

5. Tauler R., Azevedo D. de A., Lacorte S., Cespedes R., Viana P. \& Barcelo D. (2001). Organic pollutants in surface waters from Portugal using chemometric interpretation. Environmental Technology 22(9): 1043-1054.

6. U.S. Environmental Protection Agency (1992). Pesticides: Analytical Methods and Procedures, Index of Environmental Chemistry Methods (ECM) No. 422005-01.

7. Cochrane W.P. \& Maybury R.B. (1981). Environmental applications of the electron-capture detector - pesticides. Journal of Chromatography Library 20: 205-240.

8 Fillion J., Sauve F. \& Selwyn J. (2000). Multiresidue method for the determination of residues of 251 pesticides in fruits and vegetables by gas chromatography/mass spectrometry and liquid chromatography with fluorescence detection. Journal of AOAC International 83(3):698-713.

9. Martin-Esteban A., Fernandez P., Camara C., Kramer G.N. \& Maier E.A. (1997). Preparation, homogeneity, and stability of polar pesticides in freeze-dried water interlaboratory exercise. International Journal of Environmental Analytical Chemistry 67(1-4): 125-141.

10. Krasnova A.I., Eremin S.A., Natangelo M., Tavazzi S. \& Benfenati E. (2001). A polarization fluorescence immunoassay for the herbicide propanil. Analytical Letters 34(13): 2285-2301.

11. Tschmelak J., Proll G. \& Fauglitz G. (2004). Ultra-sensitive fully automated immunoassay for detection of propanil in aqueous samples: steps of progress toward sub-nanogram per liter detection. Analytical and Bioanalytical Chemistry 379(7-8): 1004-1012.

12. Priyantha N. \& Weerabahu D. (1996). Amperometric sensor for propanil. Analytica Chimica Acta 320(2-3): 263-268.

13. Natangelo M., Tavazzi S., Fanelli R. \& Benfenati E. (1999). Analysis of some pesticides in water samples using solid-phase microextraction-gas chromatography with different mass spectrometric techniques. Journal of Chromatography A 859(2): 193-201.

14. Krasnova A.I., Krikounova V.S., Dremin S.A. \& Scekacs A. (2000). Development of soild-phase enzymelinked immunoassay for detection of propanil in rice. Vestnik Moskovskogo Universiteta Khimiya 41 : 150-152.

15. Navaratna A.N. \& Hafil A.M. (2001). Analysis of propanil (3,4-DPA) residues by electroanalytical methods. Chemistry in Sri Lanka 18:39.

16. Konstantinou I.K., Zarkadis A.K. \& Albanis T.A. (2001). Photodegradation of selected herbicides in various natural waters and solids under environmental conditions. Journal of Environmental Quality 30(1): 121-130.

17. Konstantinou I.K., Sakkas V.A. \& Albanis T.A. (2001). Photocatalytic degradation of the herbicides propanil and molinate over aqueous $\mathrm{TiO}_{2}$ suspensions: identification of intermediates and the reaction pathway. Applied Catalysis B: Environmental 34(3): 227-239.

18. Konstantinou I.K. \& Albanis T.A. (2000). Adsorptiondesorption studies of selected herbicides in soil-fly ash mixtures. Journal of Agricultural and Food Chemistry 48 : (10): 4780-4790.

19. Garrido E.M., Lima J.L.F.C., Delerue-Matos C., Borges F., Silva A.M.S. \& Brett A.M.O. (2001). Electrochemical oxidation of propanil and related $\mathrm{N}$-substituted amides. Analytica Chimica Acta 434(1): 35-41.

20. Isse A.A., Ferlin M.G. \& Gennaro A. (2005). Electrocatalytic reduction of arylethyl chlorides at silver cathodes in the presence of carbon dioxide: synthesis of 2-arylpropanoic acids. Journal of Electroanalytical Chemistry 581(1): 38-45.

21. Falciola L., Gennaro A., Isse A.A., Mussini P.R. \& Rossi M. (2006). The solvent effect in the electrocatalytic reduction of organic bromides on silver. Journal of Electroanalytical Chemistry 593(1-2): 47-56.

22. Bacon J. \& Adams R. N. (1968). Anodic oxidations of aromatic amines III. substituted anilines in aqueous media. Journal of the American Chemical Society 90(24): 65966599. 